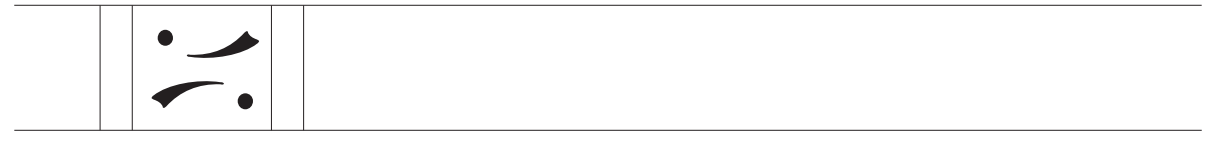

\title{
9 The Point of Study Practices Is to Discover the Kind of Questions That We "Also" Should Ask
}

\author{
Nancy Vansieleghem \\ LUCA SCHOOL OF ARTS
}

Abstract: To develop an idea of study, a lead is taken on the work of the artist Mark Dion. Dion's work, and more in particular his "Tate Thames Dig," brings together many of the elements that fosters the coming into being of matters of study. By re-enacting the 14th century cabinets of curiosity, Dion questions how modern science shape our current understanding of knowledge production. With his work, he causes an amazement for the ecology of things. At the same time he evokes a request for an entanglement between science and the world that signals an exposure to the plurality of our present. By doing so, he calls into being a way of thinking about scientific practices as study practices. Not as isolated practices that aim at discovering new knowledge, but as collective practices that give something the power to affect and make a public thinking.

Keywords: cabinet of curiosity, study, making public, multiplicity, Mark Dion

In response to the invitation of Tate museum to set up a project to celebrate the opening of the new Tate museum in London, the contemporary artist Mark Dion had the idea to exhibit the raw material collected during the two week-long digs, at Millbank, across the Thames from the old Tate Gallery, and at Bankside, just below the new Tate. With the help of volunteerswho were asked to collect and then identify anything that caught their attention-they systematically scoured the foreshores of the Thames, cumulating 
in an exhibition at Tate. The Tate Thames Dig not only generated a reflection upon the dynamic tidal flux of the river and the material it carries over the epochs of its existence, it also constitutes a public gathering around the issue of digging and grasping, and hence scientific research. In this contribution, I develop an idea of study that is inspired by Dion's artistic praxis. For me, Tate Thames Dig brings together many of the elements that foster the coming into being of matters of study. In recent philosophical literature, studying has been related to university practices. ${ }^{1}$ In this contribution, I do not return to the origins of the university, but to the origins of the 14th century cabinets of curiosity. As a re-enactment of the cabinet of curiosity, Tate Thames Dig offers many elements to consider study practices as not opposed to scientific research practices, but as practices that somehow put science into action. Drawing on Tate Thames Dig, I want to conceive study as a sensuous practice where scientific activities are intermingled with the world resulting in collective experiences of responsibility and imaginative engagement.

\section{The Origin of the Cabinet of Curiosity}

In general, we identify the cabinet of curiosity with practices of the wealthy royalties and noblemen, for which the cabinets served the end of princely display of wealth and splendour of the owner. From the very beginning, however, the cabinets were linked to curious practices, and implied a particular form of gathering around collected things from the outside world, and to make them objects of wonder. As William Schupbach points out apropos of the cabinet associated with the physic garden of Pisa: "wonder was a proper reaction for the learned as well as the uninstructed: wonder, paraphrased perhaps as inquisitive delight in novelty, mingled with awe and gratitude, was part of the natural history and natural philosophy of the time". ${ }^{2}$ It was a new kind of collecting and gathering, where the wealth of the world-previously decided upon by the monarchs and the churches-became a public enterprise and investigation. Hence, the compulsive interest in collecting expressed itself as a drive provoked by strange things that incited a quest for understanding. We speak about "animal, vegetable, and mineral specimens, anatomical oddities, medical diagrams, pictures and manuscripts describing far off landscapes, strange figures and animals or beasts from fable and myth, plans

1 Jan Masschelein, "Some Notes on the University as Studium: A Place of Collective Public Study," in Reconceptualizing Study in Educational Discourse and Practice, ed. C. Ruitenberg (New York: Routledge, 2017), 40-53.

2 Lorraine Daston, “The Factual Sensibility,” Isis 79, no. 3 (1988): 459. 
for impossible buildings and machines". ${ }^{3}$ Things in the world were taken out of their context, collected and presented together with other artefacts, and in their nonrelatedness, constituted an amazement for the world. Hence, early cabinets of curiosities resemble a profound connection with original university practices, but were unique in that they offered collective practices where amazement, perplexity, but also risk-taking, exploration, and wandering emerged in their own terms. "Bereft of labels and detached from any fixed content, the curiosities gathered in the cabinets 'resembled rumours', 'garbled messages', or 'snatches of muttered speech'." The purpose of collecting was not to represent the universe in a microcosm. The cabinets exist mainly in defying any form of classification. Objects may have been listed systematically, they were displayed to maximize heterogeneity. The collected objects were alike in being unlike. They were miscellanies, but not arbitrary miscellanies. It was in the pursuit of wonder that the deliberate diversity of the objects in the cabinet found its rationale. Hence, the work of the collector contrasted with the natural philosopher, in that the work of the latter was empirical, not factual. As Lorraine Daston states: "Observations of nature occurred aplenty, but they were firmly lodged in the context of confirmation or instruction (...). Observations proved or illustrated or even contracted a given theory but were never presented naked on their own, to await some future, as-yet-unformulated theory". ${ }^{5}$ In contrast, the cabinet of curiosity, referred to an arrangement that disturbs, questions, or even disrupts all kinds of stabilizations, fixations or crystallizations. It constituted the opening of a curious gaze and experimental life.

The reality they depict is a nominalist one of individuals instead of categories, of cases that break the rules of the normal and predictable, of irreducible diversity (...). The objects are improbable, chosen less for intrinsic beauty or scientific significance than for sheer contrast with the prosaic and mundane (...). Collectors carefully selected and arranged their objects to hone that edge; to draw a gasp of surprise from even the most well-travelled visitor. It was not the objects themselves but rather the response they were intended to evoke that impressed the contents of the cabinet with a certain unity. Wide-eyed with wonder and open-mouthed with surprise, the admiring visitor paid the collector the sincerest compliment of speechlessness $(\ldots){ }^{6}$

3 Hans Ulrich Obrist, Ways of Curating (UK: Penguin Books, 2015), 40.

4 Tony Bennet, "Pedagogic Objects, Clean Eyes and Popular Instruction: On Sensory Regimes and Museum Didactics," Configurations 6, no. 3 (1998): 45-371.

5 Daston, "The Factual Sensibility," 466.

6 Daston, "The Factual Sensibility," 459. 
Thinking through the eyes of the cabinets of curiosity, as such, not only meant being sensitive to the strange and ordinary of things in the world, but also implied the presence of other people. Since the relationship between the objects was not enclosed by a classifying logic, the objects were ordered through a dialogical social practice. ${ }^{7}$ It was the individuals who gathered around the objects that gave meaning to them by connecting and placing them with other objects, transforming the "natural" into curiosities. Accordingly, the cabinets were a form of collective practices that were initiated by scholars who gathered with no other purpose than putting a new world to the test by gathering a thinking public around it.

In this contribution, I will recall these 14th century practices to the further exploration of what study practices are about and what they make possible. I will do so by a description of Dion's Tate Thames Dig as re-enactment of the cabinet of curiosity. However, it is important to note that Dion himself did not attempt to explore the meaning of study practices. His actions arose from an unease with the way a modern museum is organized, and the rules curators and art historians follow in the classification and organization of objects. $\mathrm{He}$ wanted to question the objectivity and authoritative role of scientific voices in contemporary society, tracking how social agendas and ideology crept into public discourses and knowledge production. His point is that modern science not only defines what exists, but also the way in which things can exist. Accordingly, Dion developed an artistic praxis in which he made these tensions tangible throughout a series of "pseudo" scientific and museological arrangements. Through a particular attention for the doings acted upon in these series, I provide a sketch of concrete gestures that constitute study practices. I will not describe the ideal study practice (nor study practices as an ideal), but point out the possibility to think "digging" and "collecting" practices as collective study practices. In what follows, I highlight some features that characterize study practices: exposure, putting things together and making public.

\section{Study Practice Through the Eyes of Tate Thames Dig}

\section{Fieldwork-Exposing and Being Exposed to the World}

The collecting methodology for the first phase of the project followed the established practice of field work. The attempt was to leave the institute and to collect objects found on the banks of the Thames. The practice of walking was the main activity. There was no plan or route, only a demarcation of the

7 Bennet, "Pedagogic Objects." 
area. Dion only gave brief instructions to the team of fieldwork volunteers, asking them to adopt what he calls a "scatter-gun" approach, and to collect anything that catches their attention. There was no other goal than collecting objects. Besides Dion and a few experts, most of the people were volunteers with different backgrounds: casual passengers younger than 17 and seniors older than 65 years old who were asked to participate in the dig. However, diversity played an important role, it was no starting point. His ambition was not to show how the collected material represented a kind of multiple perspective on the river and to contrast it with an individual or one-sided perspective. The choice to work with passengers, and more specifically young or elderly people, was precisely an attempt to suspend an identification with a perspective or a function. Of course, it can be noted here that this is an impossible case. That personal preferences can never be excluded. The fieldwork itself and the situation that was created, however, caused a certain alienation. An alienation that exceeds a predefined choice or will, and that puts the participants - the experts as well as the volunteers-in a position of student. The characteristics of the river as well as the spatial and temporal experiences that are connected to the act of investigating the Thames, challenged the fieldworkers' condition. The fieldwork itself, the experience of the activity of collecting, the pain in the back, the earth crawling under the nails, the length of time, the weather conditions, but also the being together with others, caused a form of exhaustion of the gaze. ${ }^{8}$ The fieldwork turned the fieldworkers into a position of undergoing: exposed to the river, allowing its meaning to come through, you could say. As such, the fieldwork aroused not so much a mode of consciousness, but a state of amazement and passivity for the way the river unfolds itself. It induced an experience of exposure that sprung from the activity of digging and walking across the river itself, and that enabled a kind of attentiveness to the truth of the visible. The repetitive conditions of the fieldwork, the efforts and the being-in-the-presence of the river opened up an attentiveness for what there is to see, instead of what we want to see: "The fieldwork became the principle activity for the collection of objects, and reflected the conditions of the River, given that material occurred as a scatter, rather than a stratigraphy". ${ }^{9}$ The changing conditions of the river, the weather, and so on confronted the participants with the question how to see, how to notice, how to attend.

8 Jan Masschelein, “Turning the City into a Milieu of Study. University Pedagogy as 'Frontline," Educational Theory 69, no. 2 (2019): 185-203.

9 Robert Williams, "Disjecta Reliquiae: The Tate Thames Dig, 1999," in Materiality, ed. P. Lange-Brendt (Cambridge: The MIT Press, 2015), 215. 
Remarkable, however, is that in a lot of research practices this part is skipped. As Robert Williams notes: "Within archaeological method this [fieldwork] is usually as a prelude to either a more detailed survey, or excavation", ${ }^{10}$ but not the starting point. As a result, it is not the material that addresses the fieldworker, but rather deficits within previously accumulated horizons that define the results. Accordingly Dion's fieldwork asks the volunteers the question what it means to do fieldwork, and how it relates to contemporary scientific research practices. What and who decides what to think, and who decides what to collect? How to see what is visible, instead of what we want to think or see? But also, how to become affected by the river?

In this sense, the fieldwork that consists of picking up what catches one's eye while walking along the river, can be seen as an attempt to strengthen one's exposure to the world, others, and oneself. It is a way of becoming present in the present, without any projection. In other words, fieldwork offers a pedagogical condition for studying. During fieldwork, the world unfolds before the fieldworker. You could say that fieldwork literally has impact.

\section{Laboratory Work-Putting Things Together}

Besides walking and collecting material to be found along the river, the Tate Thames Dig also required a sifting of the gathered materials. Accordingly, the next instruction was to bring the finds recovered from the days of beachcombing into the laboratory. The cleaning, sifting, and arranging of the material took place on a public view in a series of tents erected near the new Tate museum. In the tents, an inventory was made of what was found at Millbank and at Bankside. From start to finish, this process was predominantly executed with eyes and hands, and in collaboration with other participants (the experts and volunteers). In line with scientific methods, each object was meticulously cleaned, recorded, labeled, and stored in a box; but similar to the practices of the curiosity cabinet, there was no attempt to give closure to the collection and to make extrapolations toward grand excavations. No selection of the material took place: everything that was collected by all the participants counted, no matter how foreign and unexpected the material. The findings spanned from fossils, bottles, shards of glass, rusted metals, pottery, cow's teeth, and bones to present-day credit cards, condoms, and plastic aliens gathered at different places and different tides. Because all the objects were deemed equally important, Dion and the other participants grouped the different "species" of objects according to sub-divisions largely suggested

10 Ibid. 
by the typography of the specimens. For example, organic, glass, bone, and so on-each of which was subdivided into a large number of classes. In the case of bone: fish, large mammal, small mammal, jaw, teeth, skull, and fossil. "Rather than prescribing what can be identified and named, the ordering system develops with the finds". ${ }^{11}$ As Robert Williams suggested, "Dion's interest lays more in the way in which the actions worked through the findings, than in the results of the findings". ${ }^{12}$ Instead of trying to give meaning, it was about trying to forget the meaning and to imagine for oneself what there is to see, to hear, and to feel: experiencing that the material has no meaning in itself, but that it gets meaning through sorting and putting things together. For Dion, this refusal did not have to do with a lack of expertise. Being an artist and not a scientist could be the reason not to take up the laboratory work as it needs to be done. As he mentioned himself, "I never take on the mantel of mastery in these projects. It is always obvious that I am a dilettante struggling to find my way. As you know the tone set at a dig is pretty irreverent despite the serious labour involved". ${ }^{13}$

As such, instead of trying to find stability and fixed categories, the actions enabled miscellanies, controversies, and singularities to exist that tend to be absent or underestimated within classical taxonomies. Accordingly, the data collected in the laboratory did not lead to what is called cognitive mapping. The laboratory actions did not work upon the world, but within it. Instruments and methodologies were borrowed from sciences, but the outcome developed in ways difficult to grasp, turning the actions into an implicit interrogation of the issue of expertise. Therefore, the most important thing "learned" from the laboratory work is probably that analyzing and ordering can bring materials in each other's company across existing divisions. And hence, that a river gathers "a microcosm of centuries-old treasures and yesterday's trash in an unpredictable mix with a complete lack of hierarchy: a museum with a collection that reaches back to the Romans, its display strictly democratic and continuously in flux".${ }^{14}$ It opened up to think about a river as an ecology of unpredictable relationships and gatherings. Hence, what Dion's laboratory actions did was opening up an amazement for what the Thames is and does, at the same time, complicating a politics of classification

11 Daniel Birnbaum, "Stream of Consciousness. Mark Dion's Tate Thames Dig," Artforum 38, no. 3 (1999). https://www.artforum.com/print/199909/stream-of-consciencemark-dion-s-tate-thames-dig-593.

12 Williams, "Disjecta Reliquiae," 215.

13 Dion in Flora Vilches, "The Art of Archaeology. Mark Dion and His Dig Projects," Journal of Social Archaeology 7, no. 2 (2007): 207.

14 Birnbaum, "Stream of Consciousness." 
and definitions. The laboratory actions were copied, extrapolated, and even dramatized in such a way that they appeared as actions that forget to determine and direct our thinking toward a result, and thus have to do with us.

In other words, through a careful attention for relations, Dion interrupted usual ways of thinking and brought selective mechanisms within laboratory practices under our attention, without defining them as such: "I would never try to devalue the efforts of biologists, anthropologist or archaeologists while I often attempt to question the political and social ramifications of their work". ${ }^{15}$ Consequently, by performing scientific tactics, Dion's actions made obvious practices visual. As Shanks states about Dion's laboratory analysis: "In the mimesis, the mimicry of field (...) practices there is a disquieting slippage from amateur to professional (so too in the collaboration with professional specialists), from simulated to real (so real it is hyper real, maybe better than the original) is what disturbs and prompts the reflexion". ${ }^{16}$

This way, you could say that the studier is not so much the science expert, but the amateur who renders himself or herself sensitive to something that has no scale, as such enabling an exploration of the plurality of the present. Consequently, what makes study practices converge, is the question how to turn common sense into something strange: transforming the natural into a curiosity. This means that study practices in the first place are concerned with rendering taken-for-granted situations problematic, giving them the power to make people think.

\section{Presentation-Making Public}

Besides the exposure to the world and the river in particular, Tate Thames Dig also implied an encounter with other people. The next question consists of how to give the river the power to gather a public of people around it. The fieldwork and the laboratory work already gathered experts and volunteers of different backgrounds, in a last stage the experiment attempts to turn the discoveries into a public matter. Hence, a movement took place from the laboratory to the museum. Two huge wooden cabinets were set up in the museum, which Dion filled with the specimens combed at the banks of the Thames. He arranged the specimen in rows like words in a sentence. Objects with no apparent connection in terms of values, historical context, use, or medium were brought together in the same compartment of the cabinet. There was no labeling, no chronology, and no interpretative text other than a reference to

15 Dion in Vilches, “The Art of Archaeology," 208.

16 Shanks in Vilches, "The Art of Archaeology," 206. 
the sites where the material was gathered. The orderings Dion used prevailed the aesthetic of shape and color, of obsessive repetition, or of absurd juxtaposition. Historical identifications, scientific categorizations, and curatorial displays were blurred and disrupted with irrational perceptual procedures of aesthetics. Hence, the attempt was to suspend the idea to put the specimen together in order to recognize common meanings and narratives. Dion is less interested in displaying narrative conclusions than performing the idea that narrating things radically depends upon the way objects are being conceived and the kind of objects that are displayed. The cabinets functioned as symbiotic assemblages at whatever scale of space and time, which made the specimen become more like knots, or what Donna Haraway ${ }^{17}$ has called "critters of diverse interactive relations in dynamic complex systems, than like entities of a biology made up of pre-existing bounded units in interaction." As such, the cabinets made the audience attentive for dominant or common narratives and interactions. The cabinets put at stake the whole idea of nature as something separate from human experience. They made present how nature is constantly reinvented by humans and how dominant relations shape scientific actions. Questions like "What is the story being told here?" arose. Whose story is being told? Are there other stories possible? The story of the river, the story of knives, or the story of color?

This way, the cabinets not only caused an amazement for the ecology of a river, but evoked a request to reconceive the entanglement between science and the world as well. Clearly, what the discoveries wanted to do most is experiencing the world in its multiplicity, as an amalgam of diverse processes and narratives, thereby eschewing hierarchy. ${ }^{18}$ Hence, by bringing the river into the museum, and by realizing that we can read the publicness of the objects, the river became a public affair. Similar to the old cabinets of curiosity, the installation itself included a practice based on doubt and possibilities, on free investigation and the recognition of a contingent reality. This way we could consider the gesture of bringing the river into the museum, as a form of putting it to the test: suspending it from its common definition and context, making it naked and beautiful. This way the cabinets offered the possibility to contemplate and think in another way about the river, form a distance. Not the kind of distance that a horizon provides, but a distance that is constituted through an encounter with other people (which involves also other things).

17 Donna Haraway, Staying with the Trouble. Making kin in the Chthulucene (Durham/ London: Duke University Press, 2016), 62.

18 Birnbaum, "Stream of Consciousness." 


\section{To Study Is to Discover the Kind of Questions that We "Also" Sbould Ask}

Turning back to the question what studying consists of, I will conclude this essay by proposing to think of study as a form of digging. But not digging in order to find the truth that lies behind or beneath the surface, but rather in line with Dion's work. His digging actions did not reveal a truth or an insight, but "shadow aspects of the process to get to an essence of the desire to do those things" ${ }^{19}$ Dion's digging practices present the energetic work of holding open the possibility that something interesting is about to happen. Which is a practice, as Donna Haraway suggests, that "cultivate(s) the wild virtue of curiosity, to return to one's ability to sense and respond-and to do all this politely". Always leading "its practitioners a bit too far of the path". ${ }^{20}$ Curiosity combines both distance from and vigilance toward oneself. Hence, the purpose of digging as a form of studying, is about complicating our own thinking and the images that captivate us, but not in a way that it induces a kind of indifference to the matter. Dion looks with the objects rather than at them. As such, the digging turns basic research into a demanding practice and ability. It touches upon crucial questions regarding life on earth. Therefore, Dion does not disconnect things from the place where they are created in order to understand them better. He does not place them in a succession of causal relations but does exactly the opposite: he accomplishes things and builds the process of knowledge production in the work to make the metamorphoses available. In a way you could say that through his "inoperative" actions he gives voice to an ecology of things. Fabricated, temporary, physical or imaginative things are brought into each other's company for the purpose of complicating our thinking.

Hence, the "dilettantes" act is an ethically responsible contribution to furthering both theoretical discourse and environmental activism, opening the question what should be asked. Looking for what has been ignored because it never fit the timeline of progress. This way, studying means asking the question how to turn "the river" into an object, "not of (re)cognition, but of encounter". ${ }^{21}$ How to investigate so that the research practice does not operate as an individually absorbing device but in a way that it enables to become a public gathering? Studying, you could say, as the art of giving

19 Dion in C. Martin, “Art Shadowing Science,” Nature 448, no. 26 (2007). https:// www.nature.com/articles/448026a.

20 Haraway, Staying with the Trouble, 127.

21 Masschelein, "Turning the City into a Milieu of Study," 200. 
the issue around which we gather the power to activate thinking. Giving it "a presence that has the potential for surprising change and becoming-with". ${ }^{22}$ For "staying with the trouble on terra," to use the words of Donna Haraway. ${ }^{23}$ As such, the most difficult point is how to ask questions that evoke curiosity. How to engage the river in constructing the question that matters to it? Knowing what we want, but not knowing what the river wants. Figuring out what its ecology wants: "acting in the manner in which the other addresses you, actualizing and verifying its proposal, in the sense of rendering it true". ${ }^{24}$ As we have seen, this does not mean neglecting scientific research. Instead, the value of scientific inquiry is affirmed, but in a way that the order, priority, and goals are reversed. Hence, studying practices can be understood as transforming the researcher's relation to the truth. Practices that make the borders of what constitutes scientific practices unclear, digging anomalies or openings in our systems of knowledge production. Study practices in this sense are always partly aesthetic and poetic. In this regard, you could say that studying is first and foremost a collective practice that investigates the kind of question that we "also" should ask today through a re-enactment of the 14th-century cabinets of curiosity. A practice that not only has a transformative effect on the situation, but on the people who are engaged in it as well.

\section{Bibliography}

Bennet, Tony. "Pedagogic Objects, Clean Eyes and Popular Instruction: On Sensory Regimes and Museum Didactics." Configurations 6, no. 3 (1998): 45-371.

Birnbaum, Daniel. "Stream of Consciousness. Mark Dion's Tate Thames Dig." Artforum 38, no. 3 (1999). https://www.artforum.com/print/199909/stream-of-consciencemark-dion-s-tate-thames-dig-593.

Haraway, Donna. Staying with the Trouble. Making kin in the Chthulucene. Durham/ London: Duke University Press, 2016.

Daston, Lorraine. “The Factual Sensibility.” Isis 79, no. 3 (1988): 452-467.

Martin, C. "Art Shadowing Science.” Nature 448, no. 26 (2007). https://www.nature. com/articles/448026a.

Masschelein, Jan. "Some Notes on the University as Studium: A Place of Collective Public Study." In Reconceptualizing Study in Educational Discourse and Practice, edited by C. Ruitenberg, 40-53. New York: Routledge, 2017.

22 Ibid.

23 Haraway, Staying with the Trouble, 63.

24 Ibid. 
Masschelein, Jan. "Turning the City into a Milieu of Study. University Pedagogy as 'Frontline."' Educational Theory 69, no. 2 (2019): 185-203.

Obrist, Hans Ulrich. Ways of Curating. UK: Penguin Books, 2015.

Vilches, Flora. "The Art of Archaeology. Mark Dion and His Dig Projects." Journal of Social Archaeology 7, no. 2 (2007): 199-223.

Williams, Robert. "Disjecta Reliquiae: The Tate Thames Dig, 1999." In Materiality, edited by P. Lange-Brendt, 215-216. Cambridge: The MIT Press, 2015. 